\title{
Propofol alleviates inflammation and apoptosis in HCY-induced HUVECs by inhibiting endoplasmic reticulum stress
}

\author{
CUNLIANG JI ${ }^{1}, \mathrm{HU} \mathrm{YI}^{2}$, JING HUANG $^{2}$, \\ WENZHONG ZHANG ${ }^{3}$ and MINGZHI ZHENG ${ }^{2}$
}

\author{
${ }^{1}$ Department of Anesthesiology, Beijing Tongren Hospital, Capital Medical University, Beijing 100730; \\ ${ }^{2}$ Department of Anesthesiology, The Affiliated Zhuzhou Hospital of Xiangya School of Medicine CSU, \\ Zhuzhou Central Hospital, Zhuzhou, Hunan 412000; ${ }^{3}$ School of Safety Engineering, \\ North China Institute of Science and Technology, Langfang, Hebei 065201, P.R. China
}

Received September 16, 2020; Accepted February 2, 2021

DOI: $10.3892 / \mathrm{mmr} .2021 .11972$

\begin{abstract}
Atherosclerosis is a chronic vascular inflammatory disease, and is associated with oxidative stress and endothelial dysfunction. Homocysteine (HCY) can cause damage to endothelial cells via the enhancement of the endoplasmic reticulum stress (ERS) pathway. Propofol has a protective effect on endothelial injury and can suppress inflammation and oxidation. The purpose of the present study was to investigate the protective effect of propofol on HCY-induced inflammation and apoptosis of human umbilical vein endothelial cells (HUVECs). HCY was used to establish the endothelial injury model. Cell Counting Kit- 8 assays and flow cytometry were used to detect cell viability and apoptosis, respectively. Then, ELISA was performed to examine the expression levels of inflammatory cytokines, and the expression levels of proteins related to inflammation, apoptosis and ERS were determined via western blotting. Results showed that propofol increased cell viability, suppressed NF- $\mathrm{KB}$ signaling pathway activation and decreased the expression levels of inflammatory factors in HUVECs induced by HCY. Moreover, propofol could inhibit the expression of proteins involved in ERS, including ER chaperone $\mathrm{BiP}$ (Bip), C/EBP-homologous protein, protein kinase R-like ER kinase and inositol-requiring $1 \alpha$, and reduce cell apoptosis of HCY-induced HUVECs. However, the overexpression of Bip could reactivate ERS and the NF- $\kappa \mathrm{B}$ signaling pathway, as well as promote inflammation and cell apoptosis, when compared with HCY-treated groups. In conclusion, propofol can ameliorate inflammation and cell apoptosis of HUVECs induced by HCY via inhibiting ERS, which may provide a novel insight into the treatment of atherosclerosis.
\end{abstract}

Correspondence to: Dr Mingzhi Zheng, Department of Anesthesiology, The Affiliated Zhuzhou Hospital of Xiangya School of Medicine CSU, Zhuzhou Central Hospital, 116 Changjiang South Road, Tianyuan, Zhuzhou, Hunan 412000, P.R. China

E-mail: zhengming12z@163.com

Key words: atherosclerosis, homocysteine, human umbilical vein endothelial cells, propofol

\section{Introduction}

As a chronic vascular inflammatory disease, which is associated with oxidative stress and endothelial dysfunction, atherosclerosis mainly affects the walls of large and medium arteries, such as the aorta, carotid and coronary arteries $(1,2)$. The characteristics of atherosclerosis include lipid accumulation, inflammatory response, cell death and arterial wall sclerosis, which forms the pathological basis of ischemic heart disease (3). Therefore, it is important to identify novel therapeutic strategies for the treatment of atherosclerosis.

Homocysteine (HCY) is a sulfhydryl-containing amino acid produced via the demethylation of dietary methionine, which is rich in animal proteins (1). Previously, increased plasma HCY was confirmed to be an independent risk factor for atherosclerosis, and HCY may aggravate vascular endothelial inflammation and injure the endothelial cells of major vessels, such as the carotid artery and the aorta $(1,2)$. Therefore, HCY was used to establish an endothelial injury model in the present study.

Propofol (2, 6-diisopropyl phenol) is an intravenous general anesthetic, which is used clinically in an emulsion formulation. It is extensively used in the induction and maintenance of anesthetization and procedural sedation $(3,4)$. The functions of propofol include anti-inflammation, inhibition of the production of pro-inflammatory cytokines (5), conversion of the production of nitric oxide, suppression of neutrophil functions and anti-oxidation (5). Furthermore, propofol has been reported to upregulate the expression levels of phospholipid-transporting ATPase ABCA1, ATP-binding cassette sub-family $G$ member 1 and scavenger receptor class B member 1 via the peroxisome proliferator-activated receptor $\gamma /$ oxysterols receptor LXR- $\alpha$ signaling pathway in THP-1 macrophage-derived foam cells. Several studies have also shown the protective role of propofol in myocardial ischemia reperfusion injury in type 2 diabetic rats and its alleviating effect on the injury and apoptosis in endothelial cells (6-8).

The endoplasmic reticulum (ER) is an organelle covered by an extensive membrane network in eukaryotic cells. It plays an important role in protein synthesis, folding and transport, calcium homeostasis, lipid and steroid synthesis. A variety 
of pathological factors, such as hyperlipidemia, oxidative stress, viral infection and calcium imbalance can disturb the homeostasis of ER and cause the accumulation of misfolded or unfolded proteins in the ER cavity, which is called ER stress (ERS) (9). To alleviate this stress, the cell initiates the unfolded protein response (UPR) (10). Studies have demonstrated that ERS is associated with atherosclerosis, and plays an important role in the initiation and progression of atherosclerosis $(11,12)$. Long-term ERS can lead to apoptosis and activation of inflammatory response pathways. In cardiovascular diseases, $\mathrm{C} / \mathrm{EBP}-$ homologous protein (CHOP) is the most widely studied biomarker in the ERS-related apoptosis signaling pathway (13). The activation of the apoptotic signaling pathway mediated by CHOP and ER chaperone BiP (Bip), upregulates the expression levels of pro-apoptotic members of the Bcl-2 family and induces apoptosis (13). As atherosclerosis progresses, the UPR cannot control ERS, and the expression of CHOP increases, eventually activating its induced apoptosis signaling pathway. ERS can also activate the NF- $\mathrm{KB}$ pathway and the NACHT LRR and PYD domains-containing protein 3 inflammasome, and increase the expression levels of a large number of inflammatory molecules, such as TNF- $\alpha$ and IL-1 $\beta$; therefore, it can trigger inflammatory responses (12). It has been confirmed that ERS-mediated apoptosis and inflammation are widely involved in all stages of atherosclerotic development (14).

The aim of the present study was to investigate whether propofol could inhibit the injury of endothelial cells induced by HCY and the potential mechanism involved.

\section{Materials and methods}

Cell culture. Human umbilical vein endothelial cells (HUVECs, PCS-100-010 ${ }^{\mathrm{TM}}$ ) were purchased from the American Type Culture Collection, thawed at $37^{\circ} \mathrm{C}$ for $2 \mathrm{~min}$, then transferred into a tube containing $5 \mathrm{ml}$ RPMI-1640 medium (Gibco; Thermo Fisher Scientific, Inc.), followed by centrifugation at $1,000 \mathrm{x}$ g and $4^{\circ} \mathrm{C}$ for $5 \mathrm{~min}$. The supernatant was removed, then the cells were re-suspended in RPMI-1640 medium containing $100 \mathrm{U} / \mathrm{ml}$ penicillin, $100 \mu \mathrm{g} / \mathrm{ml}$ streptomycin and 10\% FBS (Gibco; Thermo Fisher Scientific, Inc.). Subsequently, they were transferred into a $25-\mathrm{cm}$ flask and incubated at $37^{\circ} \mathrm{C}$ in an humidified incubator with $5 \% \mathrm{CO}_{2}$. The medium was replaced every 2 days. When the cells reached $80 \%$ confluence, they were washed with PBS twice, then $0.25 \%$ trypsin $(1 \mathrm{ml})$ was added. After attachment, cells (70-80\% confluence) were exposed to $2.5 \mathrm{mmol} / \mathrm{l} \mathrm{HCY}$ (Sigma-Aldrich; Merck KGaA) at $37^{\circ} \mathrm{C}$ for $48 \mathrm{~h}$ to construct the endothelial cell injury model (2). For HCY and propofol (Sigma-Aldrich; Merck KGaA) co-treatment, adherent cells were pre-treated with indicated concentrations $(12.5,25,50$, 100 and $200 \mu \mathrm{M}$ ) of propofol at $37^{\circ} \mathrm{C}$ for $2 \mathrm{~h}$, followed by exposure to $2.5 \mathrm{mmol} / 1 \mathrm{HCY}$ for $48 \mathrm{~h}$. Untreated cells were used as the control group. Then, cells were collected for the following analysis.

Cell transfection. For Bip overexpression, overexpression plasmids (pcDNA3.1-Bip; ov-Bip) were purchased from Shanghai GenePharma Co., Ltd. The pcDNA3.1 empty vector (Shanghai GenePharma Co., Ltd.) was used as a negative control (NC). Briefly, Lipofectamine ${ }^{\circledR} 2000$ (Invitrogen; Thermo Fisher
Scientific. Inc.) was mixed with $20 \mu \mathrm{g}$ plasmids, which was then added to the cells at 70-80\% confluence and incubated for $6 \mathrm{~h}$ at $37^{\circ} \mathrm{C}$. Subsequently, cells were cultured in RPMI- 1640 medium and at 48 -h post-transfection, the cell samples were used for subsequent experimentation.

Cell Counting Kit-8 (CCK-8) assay. Briefly, the HVUECs $\left(2 \times 10^{3}\right.$ cells per well) were seeded into a 96-well plate and incubated at $37^{\circ} \mathrm{C}$. After attachment, cells were pre-treated with or without $12.5,25,50,100$ and $200 \mu \mathrm{M}$ propofol at $37^{\circ} \mathrm{C}$ for $2 \mathrm{~h}$, followed by exposure to $2.5 \mathrm{mmol} / 1 \mathrm{HCY}$ for $48 \mathrm{~h}$. Subsequently $10 \mu \mathrm{l}$ CCK-8 reagent (Dojindo Molecular Technologies, Inc.) was added to each well and incubated for $2 \mathrm{~h}$ at $37^{\circ} \mathrm{C}$. Then, the absorbance of the cells was measured at $450 \mathrm{~nm}$ using a microplate reader (BioTek Instruments, Inc.).

ELISA. To determine the concentrations of TNF- $\alpha$ (cat. no. F02810), IL-1 $\beta$ (cat. no. F01220) and IL-6 (cat. no. F01310) in the supernatant of the HUVECs, corresponding ELISA kits (Shanghai Xitang Biotechnology Co., Ltd.) were used according to the manufacturer's instructions. The optical density at $450 \mathrm{~nm}$ was measured using a microplate reader (Bio-Rad Laboratories, Inc.), then a standard curve was created.

Western blot analysis. Total cell protein was extracted using RIPA lysis (Beyotime Institute of Biotechnology), then the concentration was determined using the BCA method. Protein $(50 \mu \mathrm{g})$ was added to the SDS loading buffer, and after the protein samples were heated in a water bath for $5 \mathrm{~min}$, they were separated via SDS-PAGE on a $10 \%$ gel at $60 \mathrm{~V}$ for $40 \mathrm{~min}$ and $110 \mathrm{~V}$ for $60 \mathrm{~min}$. Separated proteins were then transferred onto a PVDF membrane. After washing with PBS, the PVDF membrane was blocked with $50 \mathrm{~g} / \mathrm{l}$ skimmed milk at $25^{\circ} \mathrm{C}$ for $1 \mathrm{~h}$. Following which, the membrane was incubated overnight at $4^{\circ} \mathrm{C}$ with primary antibodies against NF-кB-p65 (cat. no. ab16502; 1:2,000; Abcam), phosphorylated (p)-IкB $\alpha$ (cat. no. ab92700; 1:1,000; Abcam), Bax (cat. no. ab32503; 1:1,000; Abcam), cleaved caspase-3 (cat. no. ab2302; 1:1,000; Abcam), Bcl-2 (cat. no. ab32124; 1:1,000; Abcam), Bip (cat. no. 3177; 1:1,000; Cell Signaling Technology, Inc.), CHOP (cat. no. 2895; 1:1,000; Cell Signaling Technology, Inc.), p-protein kinase R (PKR)-like ER kinase (PERK; cat. no. 3179; 1:1,000; Cell Signaling Technology, Inc.), PERK (cat. no. 5683; 1:1,000; Cell Signaling Technology, Inc.) and inositol-requiring $1 \alpha$ (IRE1 $\alpha$; cat. no. 3294; 1:1,000; Cell Signaling Technology, Inc.). After the membrane was washed with TBS with 5\% Tween-20 (TBST) three times, a goat anti-rabbit IgG (cat. no. ab205718; 1:10,000; Abcam) and goat anti-mouse IgG (cat. no. ab6789; 1:10,000; Abcam) secondary antibodies were added to the PVDF membrane at $37^{\circ} \mathrm{C}$ for $2 \mathrm{~h}$. After TBST was used to wash the membrane, ECL agent (Thermo Fisher Scientific, Inc.) was added and the images were captured using a Bio-Rad chemiluminescence imager (Bio-Rad Laboratories, Inc.). Protein expression levels were semi-quantified using Image-Pro Plus software version 6.0 (Roper Technologies, Inc.).

Flow cytometry. A total of $1.5 \times 10^{6}$ cells were incubated with $0.25 \%$ trypsin, harvested and rinsed twice with pre-chilled PBS. 

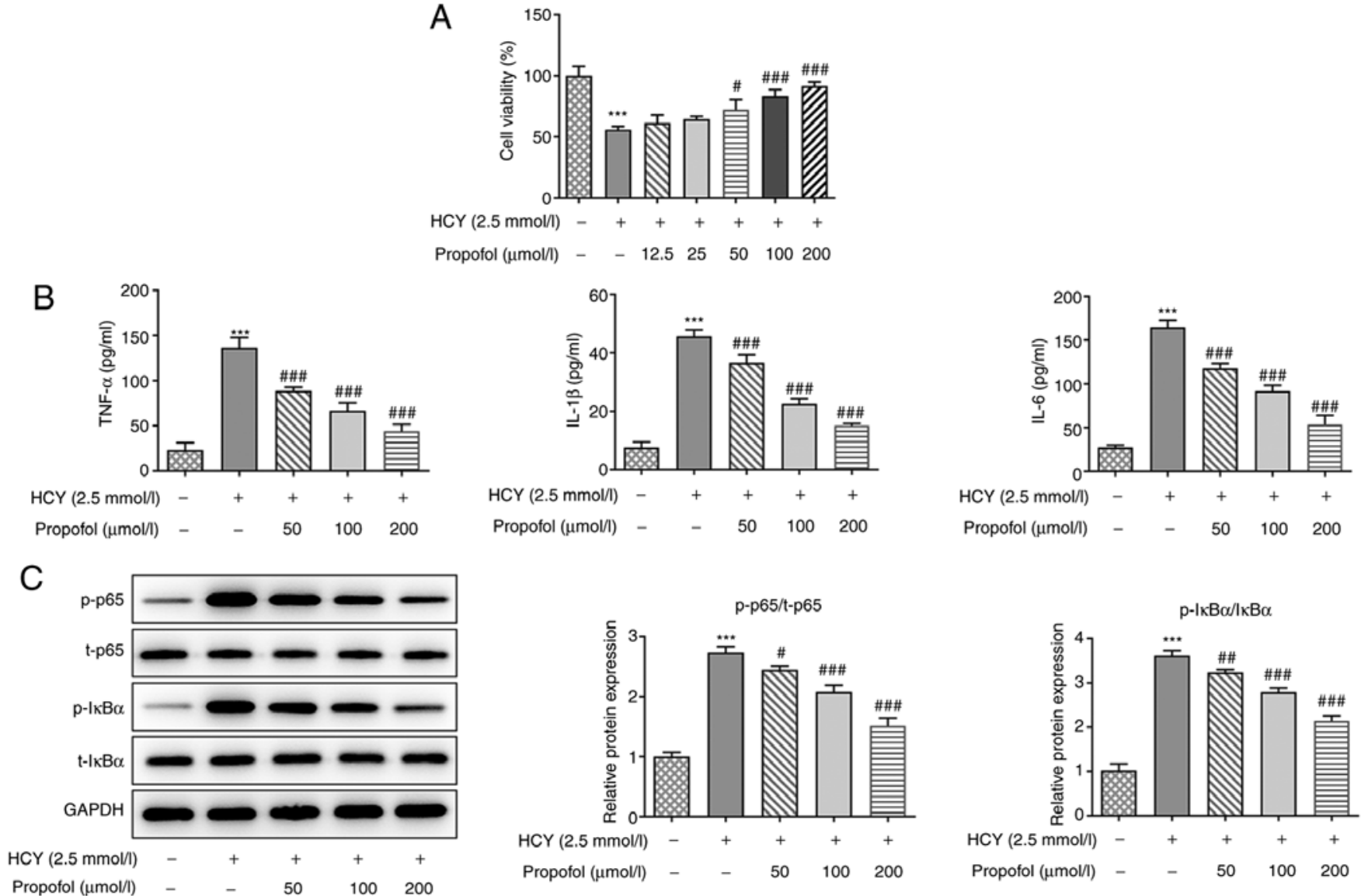

Figure 1. Effect of propofol on HCY-induced NF-kB signaling activation and inflammation in HUVECs. (A) HUVECs were pretreated with different concentrations of propofol for $2 \mathrm{~h}$ and stimulated with $2.5 \mathrm{mmol} / 1 \mathrm{HCY}$ for $48 \mathrm{~h}$, then the cell viability was measured using a Cell Counting Kit-8 assay. (B) HUVECs were pretreated with different concentrations of propofol for $2 \mathrm{~h}$ and stimulated with $2.5 \mathrm{mmol} / 1 \mathrm{HCY}$ for $48 \mathrm{~h}$, then the concentrations of TNF- $\alpha$, IL- $1 \beta$ and IL-6 in the culture medium was measured using ELISA kits. (C) HUVECs were pretreated with different concentrations of propofol for $2 \mathrm{~h}$ and stimulated

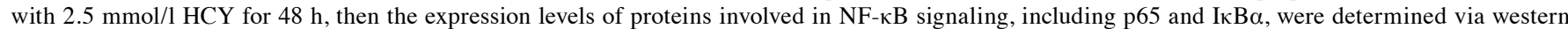
blotting. ${ }^{* * *} \mathrm{P}<0.001$ vs. control group; ${ }^{\#} \mathrm{P}<0.05,{ }^{\# \#} \mathrm{P}<0.01$ and ${ }^{\# \# \#} \mathrm{P}<0.001$ vs. HCY group. HCY, homocysteine; HUVECs, human umbilical vein endothelial cells; p-, phosphorylated; t-, total.

Then, the apoptotic rate was evaluated with the Annexin V-FITC Apoptosis Detection kit (BioLegend, Inc.). Briefly, the transfected cells were resuspended in $100 \mu \mathrm{l}$ binding buffer prior to counterstaining with $5 \mu \mathrm{l}$ Annexin V-FITC and $5 \mu \mathrm{l}$ PI solution at room temperature in the dark for $15 \mathrm{~min}$. Then, the stained cells were analyzed using a flow cytometer (FACScan; BD Biosciences). The data was analyzed using CellQuest ${ }^{\mathrm{TM}}$ software v.5.1 (BD Biosciences) to assess early + late apoptosis.

Statistical analysis. All data are presented as the mean \pm standard deviation from three independent repeated experiments. Statistical data analysis was performed with SPSS v23.0 (IBM Corp.) and GraphPad Prism v5.0 (GraphPad Software, Inc.) software. Statistical differences between multiple groups were analyzed using one-way ANOVA followed by Tukey's post hoc test. $\mathrm{P}<0.05$ was considered to indicate a statistically significant difference.

\section{Results}

Propofol ameliorates HCY-induced HUVEC cell injury. To investigate the dysfunction caused by HCY in HUVECs, the cell viability of HUVECs was detected. As shown in Fig. 1A, the cell viability of cells treated with HCY was significantly decreased compared with that in the control group; however, the addition of 50-200 $\mu \mathrm{mol} / 1$ propofol enhanced cell viability in a dose-dependent manner. Therefore, propofol at 50, 100 and $200 \mu \mathrm{mol} / 1$ was chosen for further experimentation.

Propofol decreases the concentration of inflammatory factors in HCY-induced HUVECs. As NF- $\mathrm{BB}$-mediated endothelial cell activation and vascular inflammation are central to the initiation and progression of atherosclerosis (15), the expression levels and release of pro-inflammatory factors were investigated. Following propofol pretreatment for $2 \mathrm{~h}$ and the induction of cell injury with $2.5 \mathrm{mmol} / \mathrm{l} \mathrm{HCY}$ for $4 \mathrm{~h}$, the concentration of TNF- $\alpha$, IL- $1 \beta$ and IL- 6 in the HUVECs were detected using ELISA, and the protein expression levels of p-NF- $\kappa \mathrm{B}-\mathrm{p} 65$ and $\mathrm{p}-\mathrm{I} \kappa \mathrm{B} \alpha$ were detected using western blot analysis. Compared with those in the control group, the concentrations of TNF- $\alpha$, IL- $1 \beta$ and IL- 6 were decreased following pretreatment with propofol, in a dose-dependent manner (Fig. 1B). Furthermore, as shown in Fig. 1C, it was found that HCY significantly upregulated the ratio of p-p65 and $\mathrm{p}-\mathrm{I} \kappa \mathrm{B} \alpha$, while increasing doses of propofol reversed the effects of HCY. The results suggested that propofol 
A

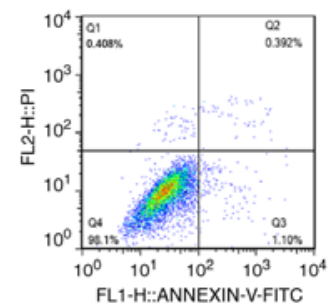

$\operatorname{HCY}(2.5 \mathrm{mmol})$

Propofol ( $\mu \mathrm{mol})$
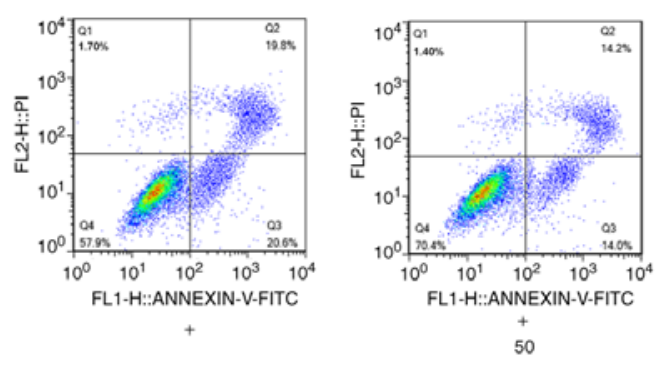

50

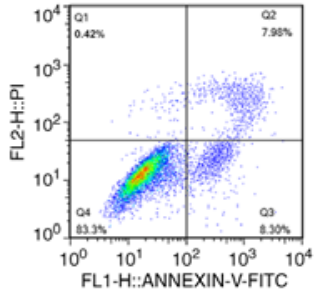

100

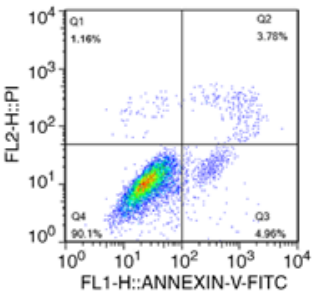

200

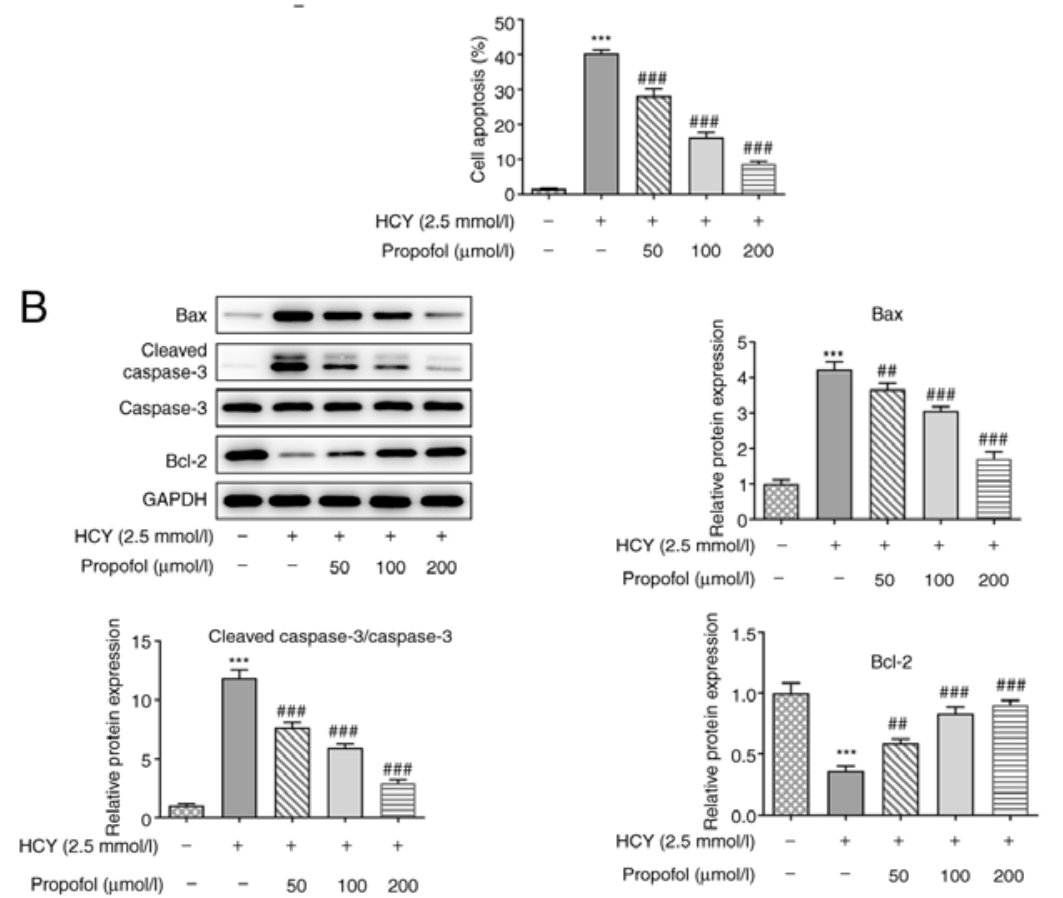

Figure 2. Effect of propofol on HCY-induced apoptosis in HUVECs. (A) HUVECs were pretreated with different concentrations of propofol for $2 \mathrm{~h}$ and stimulated with $2.5 \mathrm{mmol} / 1 \mathrm{HCY}$ for $48 \mathrm{~h}$, then the ratio of apoptotic cells was detected by flow cytometry. (B) HUVECs were pretreated with different concentrations of propofol for $2 \mathrm{~h}$ and stimulated with $2.5 \mathrm{mmol} / 1 \mathrm{HCY}$ for $48 \mathrm{~h}$, then the expression levels of proteins related to apoptosis, including Bax, cleaved caspase-3/caspase-3 and Bcl-2, were detected via western blotting. ${ }^{* * * *} \mathrm{P}<0.001$ vs. control group; ${ }^{\# \#} \mathrm{P}<0.01$ and ${ }^{\# \# \#} \mathrm{P}<0.001$ vs. HCY group. HCY, homocysteine; HUVECs, human umbilical vein endothelial cells.

could decrease the production of inflammatory cytokines in HCY-induced HUVECs by inactivating the NF- $\mathrm{BB}$ signaling pathway.

Propofol decreases cell apoptosis in HCY-induced HUVECs. Following pretreatment with propofol for $2 \mathrm{~h}$ and induction of cell injury with $2.5 \mathrm{mmol} / \mathrm{l} \mathrm{HCY}$ in the HUVECs for $48 \mathrm{~h}$, apoptosis was measured using flow cytometry. As shown in Fig. 2A, cell apoptosis was increased in the HCY group compared with that in the control group; however, apoptosis gradually decreased when the cells, induced by HCY, were pretreated with increasing concentrations of propofol. Then, western blotting was performed to detect the expression levels of the apoptosis-related proteins, Bax, cleaved caspase- 3 and Bcl-2. As shown in Fig. 2B, the protein expression levels of Bax and cleaved caspase-3 were downregulated, while that of Bcl-2 was upregulated, as a result of increasing concentrations of propofol pretreatment. These results indicated that propofol could decrease HUVEC apoptosis induced by HCY.

Propofol decreases ERS in HCY-induced HUVECs. Western blot analysis was utilized to assess the effect of propofol on the expression levels of ERS-related proteins. HCY increased the protein expression levels of Bip and CHOP in HUVECs, indicating that HCY increased ERS (Fig. 3A). However, pretreatment of HUVECs with increasing concentrations of propofol alleviated the increased protein expression levels of Bip and CHOP in a dose-dependent manner. Next, the protein expression levels of p-PERK and p-IRE $\alpha$ were detected, and the results showed that their expression levels in HCY-induced HUVECs were increasingly attenuated by propofol (Fig. 3B). These results suggested that propofol could decrease the expression level of proteins involved in ERS in HUVECs induced by HCY.

Overexpression of Bip reverses the inhibitory effect of propofol on HCY-induced HUVEC ERS. Then, the Bip overexpression plasmid was constructed and western blotting confirmed its transfection efficiency compared with the NC (Fig. 4A). Subsequently, propofol, at $200 \mu \mathrm{mol} / 1$, was selected for the next experiments to examine the effect of Bip overexpression on the functions of propofol. As shown in Fig. 4B, the cell viability of HCY-induced HUVECs was enhanced by pretreatment with propofol; however, it decreased when 

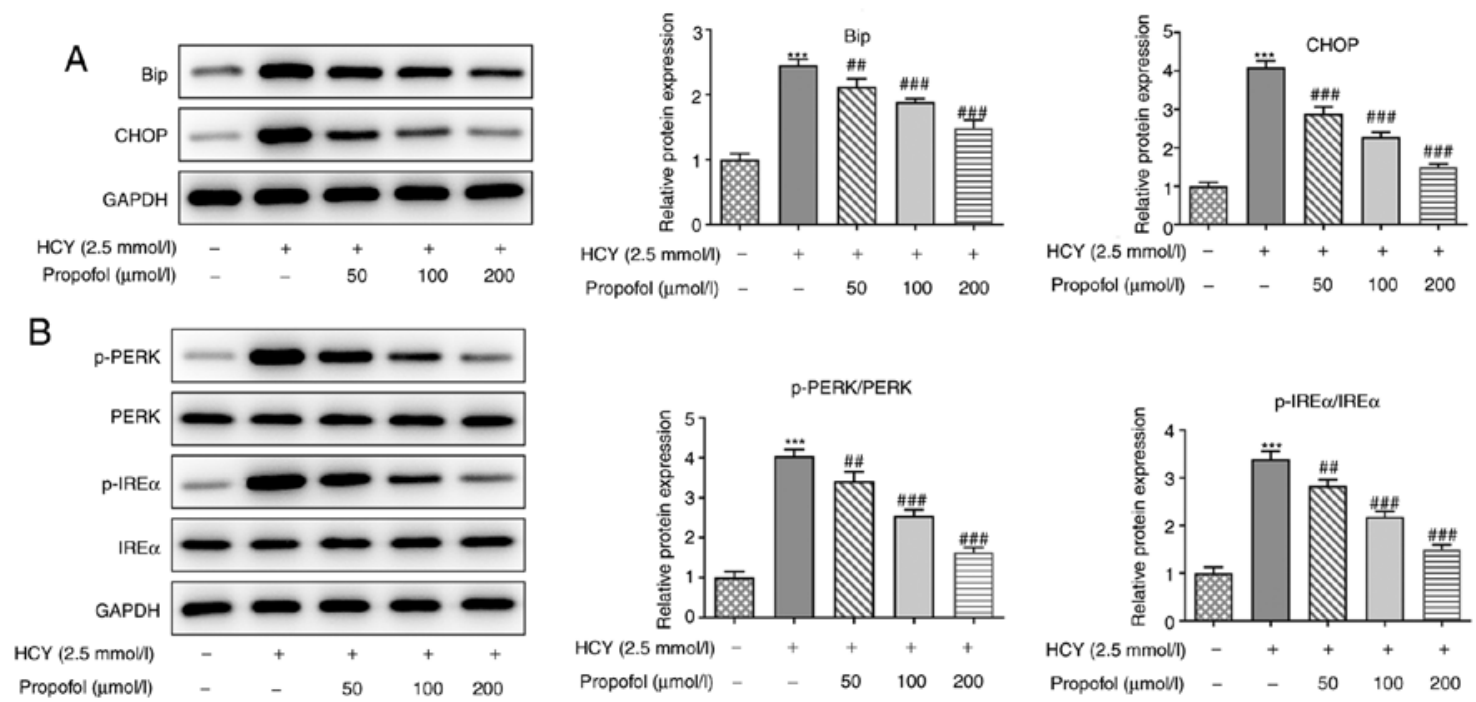

Figure 3. Effect of propofol on the expression levels of proteins related to ERS in HCY-treated HUVECs. HUVECs were pretreated with different concentrations of propofol for $2 \mathrm{~h}$ and stimulated with $2.5 \mathrm{mmol} / \mathrm{l} \mathrm{HCY}$ for $48 \mathrm{~h}$. Then, the expression levels of proteins involved in ERS were detected via western blotting, including (A) Bip and CHOP, and (B) p-PERK and p-IRE $\alpha .{ }^{* * *} \mathrm{P}<0.001$ vs. control group; ${ }^{\# \#} \mathrm{P}<0.01$ and ${ }^{\# \# \#} \mathrm{P}<0.001$ vs. HCY group. HCY, homocysteine; HUVECs, human umbilical vein endothelial cells; ERS, endoplasmic reticulum stress; p-, phosphorylated; Bip, ER chaperone BiP; CHOP, C/EBP-homologous protein; PERK, protein kinase R-like ER kinase; IRE $\alpha$, inositol-requiring $1 \alpha$.

A

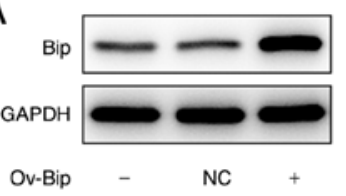

C

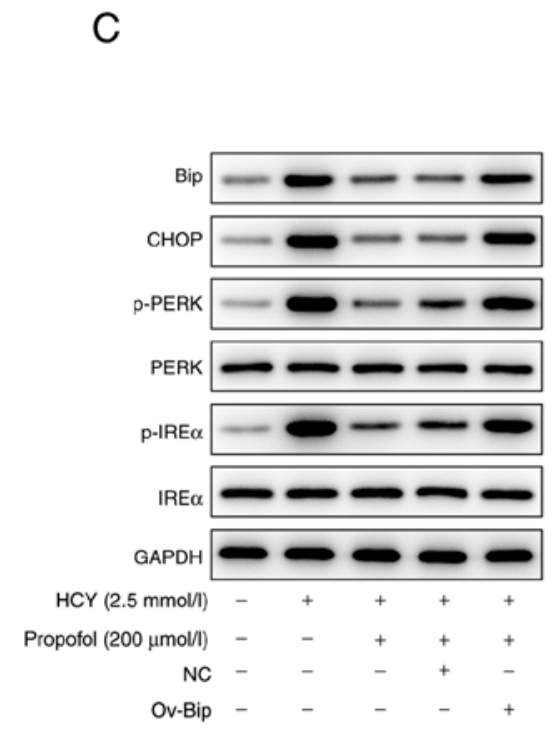

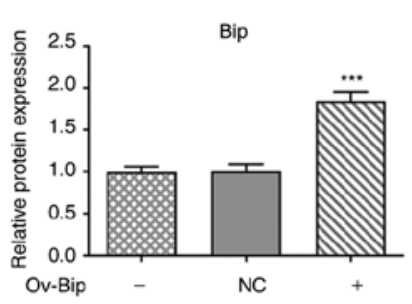

B

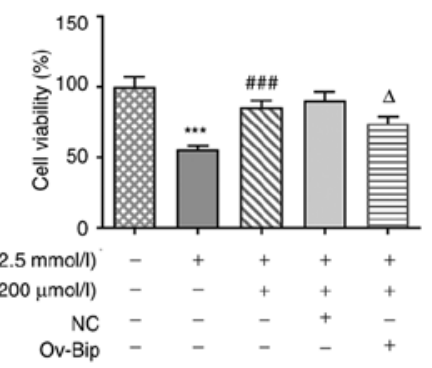

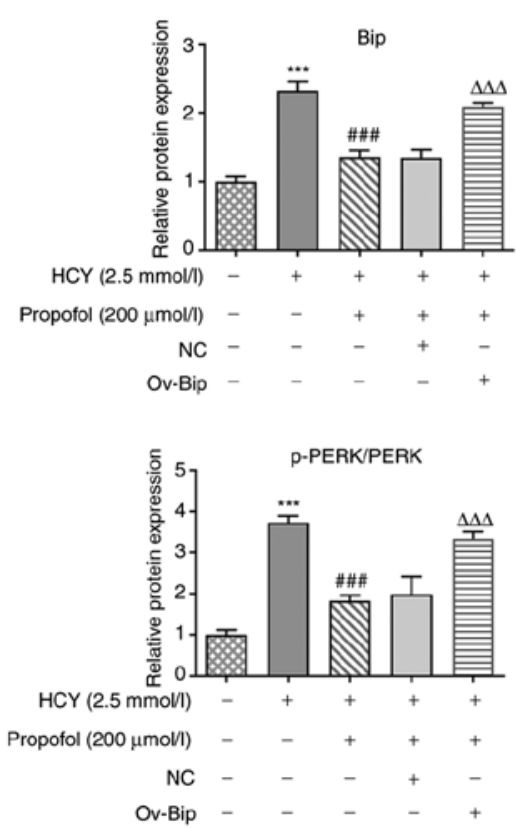

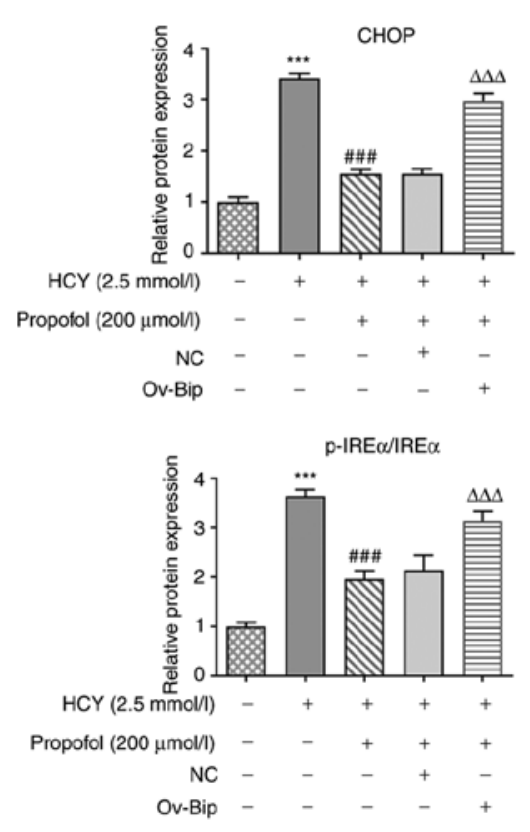

Figure 4. Effect of Bip overexpression on the propofol-induced reduction in the expression of ERS-related proteins in HCY-treated HUVECs. (A) HUVECs were transfected with ov-Bip or NC vector, then the protein expression of Bip was detected by western blotting. (B) HUVECs transfected with ov-Bip or NC vectors were pretreated with $200 \mu \mathrm{mol} / 1$ propofol for $2 \mathrm{~h}$ and stimulated with $2.5 \mathrm{mmol} / 1 \mathrm{HCY}$ for $48 \mathrm{~h}$, then cell viability was detected using a Cell Counting Kit- 8 assay. (C) HUVECs transfected with ov-Bip or NC vectors were pretreated with $200 \mu \mathrm{mol} / 1$ propofol for $2 \mathrm{~h}$ and stimulated with $2.5 \mathrm{mmol} / 1 \mathrm{HCY}$ for $48 \mathrm{~h}$, then the protein expression levels of Bip, CHOP, p-PERK/PERK and p-IRE $\alpha /$ IRE $\alpha$ were detected via western blotting. ${ }^{* * *} \mathrm{P}<0.001 \mathrm{vs}$. control group;

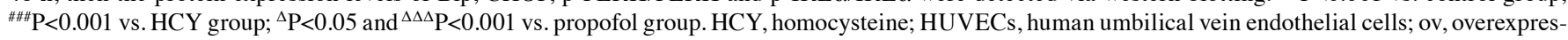
sion vector; NC, negative control; p-, phosphorylated; Bip, ER chaperone BiP; CHOP, C/EBP-homologous protein; PERK, protein kinase R-like ER kinase; IRE $\alpha$, inositol-requiring $1 \alpha$. 

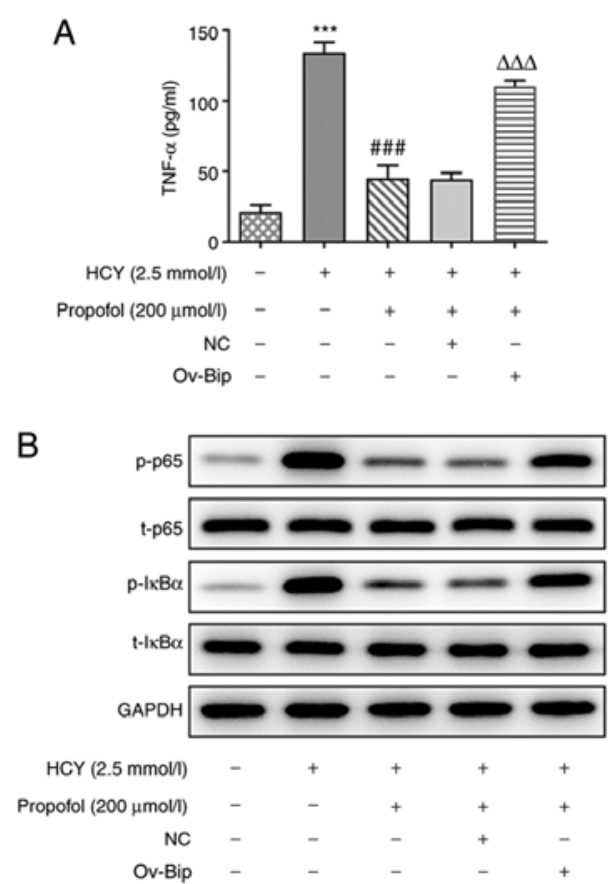
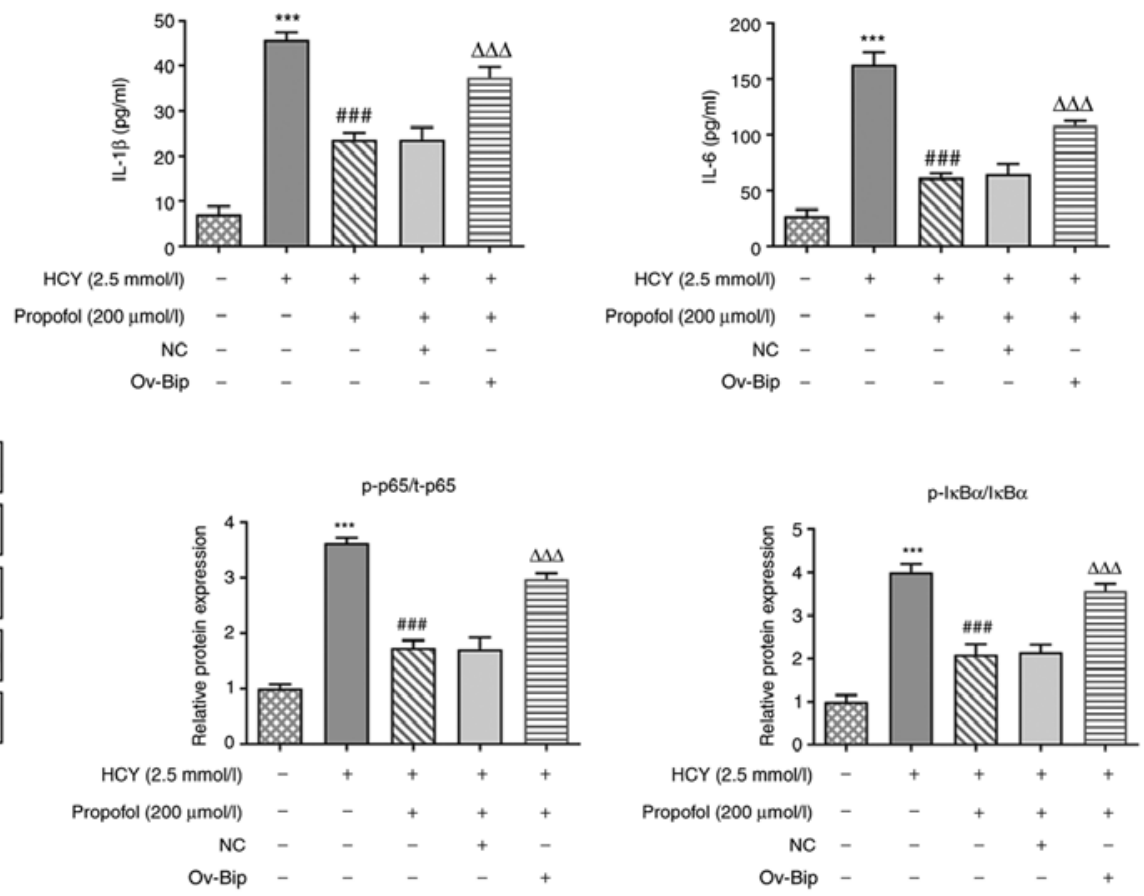

Figure 5. Effect of Bip overexpression on the propofol-induced suppression of inflammation and NF- $\mathrm{kB}$ signaling activation in HCY-treated HUVECs. (A) HUVECs transfected with ov-Bip or NC vectors were pretreated with $200 \mu \mathrm{mol} / 1$ propofol for $2 \mathrm{~h}$ and stimulated with $2.5 \mathrm{mmol} / 1 \mathrm{HCY}$ for $48 \mathrm{~h}$, then the concentrations of TNF- $\alpha$, IL-1 $\beta$ and IL- 6 in the culture medium was measured using ELISA kits. (B) HUVECs transfected with ov-Bip or NC vectors were pretreated with $200 \mu \mathrm{mol} / 1$ propofol for $2 \mathrm{~h}$ and stimulated with $2.5 \mathrm{mmol} / 1 \mathrm{HCY}$ for $48 \mathrm{~h}$, then the expression levels of proteins involved in NF- $\mathrm{KB}$ signaling, including p65 and IкB $\alpha$, were determined via western blotting. ${ }^{* * * *} \mathrm{P}<0.001$ vs. control group; ${ }^{\# \# ~} \mathrm{P}<0.001$ vs. HCY group; ${ }^{\Delta \Delta \Delta} \mathrm{P}<0.001$ vs. propofol group. HCY, homocysteine; HUVECs, human umbilical vein endothelial cells; ov, overexpression vector; NC, negative control; p-, phosphorylated; t-, total; Bip, ER chaperone BiP.

ov-Bip was transfected into the cells. Next, the expression levels of ERS-related proteins were determined, as shown in Fig. 4C, the protein expression levels of p-PERK and p-IRE $\alpha$ in HCY-induced HUVECs were downregulated following pretreatment with propofol. However, transfection with ov-Bip, in these cells, increased the protein expression levels of p-PERK and p-IRE $\alpha$. These results suggested that overexpression of Bip could reverse the inhibitory effect of propofol on HCY-induced cell viability impairment and ERS in HUVECs.

Overexpression of Bip reverses the inhibitory effect of propofol on $N F-\kappa B$ signaling-mediated inflammatory responses in HUVECs induced by HCY. ELISA was performed to detect the concentrations of TNF- $\alpha$, IL-1 $\beta$ and IL-6. Compared with that in the HCY group, pretreatment with propofol in HCY-induced HUVECs could downregulate the concentrations of inflammatory cytokines, which could be reversed by the overexpression of Bip (Fig. 5A). Next, the pro-inflammatory proteins in the $\mathrm{NF}-\mathrm{KB}$ signaling pathway were investigated, and western blot analysis showed that the ratio of p-p65 and p-IкB $\alpha$ was higher in the HCY group compared with that in the control group, and pretreatment with propofol downregulated their expression levels (Fig. 5B). However, transfection with ov-Bip could reverse these effects. Thus, overexpression of Bip could reverse the inhibitory effect of propofol on the expression of $\mathrm{NF}-\kappa \mathrm{B}$ signaling-mediated inflammatory factors in HUVECs induced by HCY.

Overexpression of Bip reverses the inhibitory effects of propofol on cell apoptosis in HCY-induced HUVECs.
To further investigate whether propofol could reduce HCY-induced cell apoptosis by regulating ERS, flow cytometry was utilized. The results showed that compared with that in the HCY group, pretreatment with propofol inhibited cell apoptosis in HCY-induced HUVECs, but transfection with ov-Bip promoted cell apoptosis of these cells (Fig. 6A). Furthermore, pretreatment with propofol downregulated the protein expression levels of Bax and cleaved caspase- 3 and upregulated the expression of Bcl-2, which could be reversed by the overexpression of Bip (Fig. 6B). The results showed that overexpression of Bip could reverse the inhibitory effects of propofol on cell apoptosis in HCY-induced HUVECs.

\section{Discussion}

The dysfunction of the endothelium, which is an emergent and complex system, is involved in the pathogenesis of all types of cardiovascular diseases and it occurs in response to cardiovascular risk factors (16). Previous investigations have shown that endothelial dysfunction occurs prior to and throughout the development of atherosclerosis (17). Furthermore, dysfunction of the endothelial cells, which occurs in the process of lesion formation, at the earliest time, could stimulate the development of atherosclerosis, demonstrating that endothelial dysfunction is a biomarker to predict the onset of atherosclerosis (18-20).

$\mathrm{HCY}$ is the byproduct of a high number of biological processes and an independent risk factor for cardiovascular disease, which was previously confirmed by some clinical trials (21). Furthermore, some studies identified its role in inducing inflammation, apoptosis in endothelial cell culture 
A

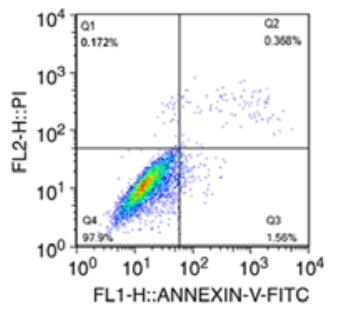

$\mathrm{HCY}(2.5 \mathrm{mmol} /)$

Propofol $(200 \mu \mathrm{mol} / \mathrm{l})$ Ov-Bip
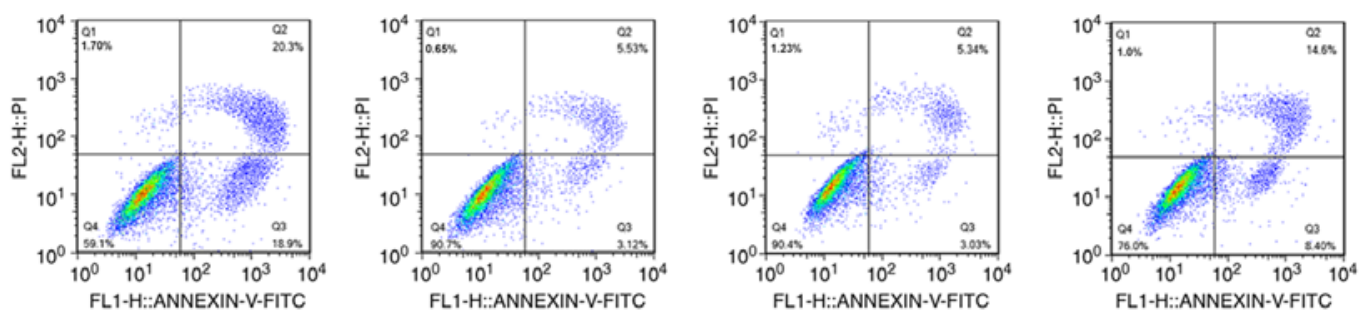

$+$

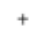

$+$
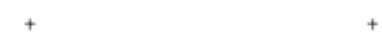

$-$

$+$

B

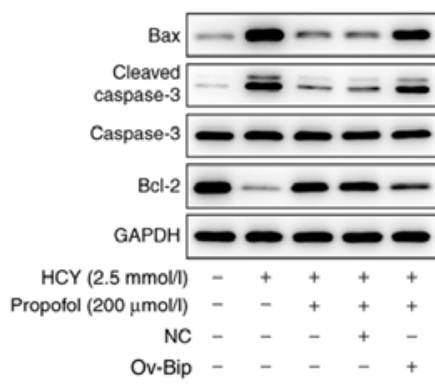

$\mathrm{BCl}-2$

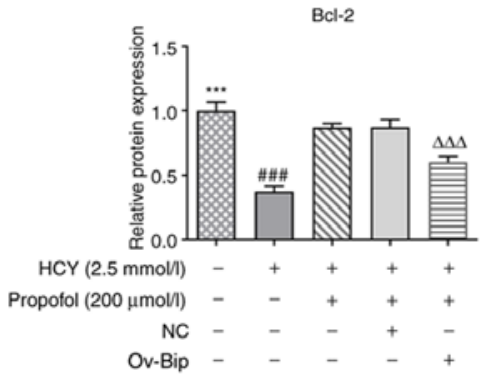

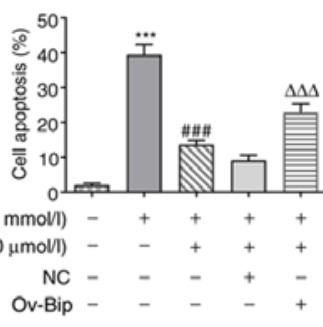
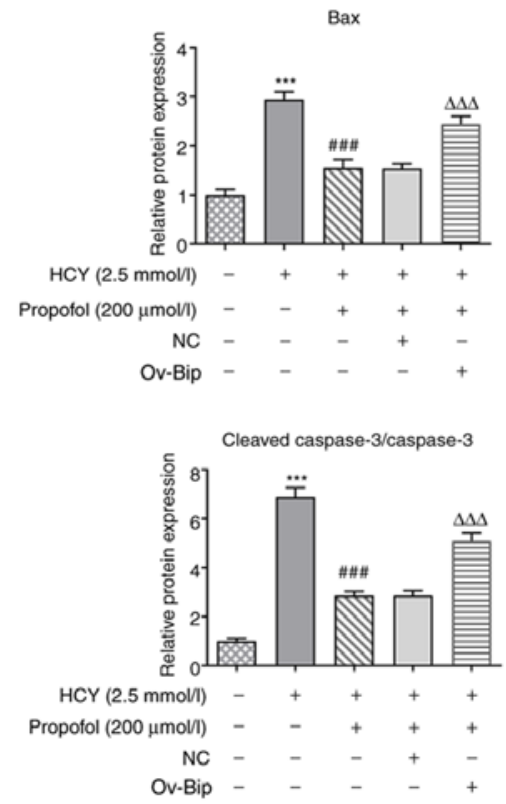

Figure 6. Effect of Bip overexpression on the propofol-induced inhibition of apoptosis in HCY-treated HUVECs. HUVECs transfected with ov-Bip or NC vectors were pretreated with $200 \mu \mathrm{mol} / 1$ propofol for $2 \mathrm{~h}$ and stimulated with $2.5 \mathrm{mmol} / \mathrm{l} \mathrm{HCY}$ for $48 \mathrm{~h}$. (A) The ratio of apoptotic cells was detected by flow cytometry and (B) the expression levels of proteins related to apoptosis, including Bax, cleaved caspase-3/caspase-3 and Bcl-2 were determined via western blotting. ${ }^{* * *} \mathrm{P}<0.001$ vs. control group; ${ }^{\# \#} \mathrm{P}<0.001$ vs. HCY group; ${ }^{\Delta \Delta \Delta} \mathrm{P}<0.001$ vs. propofol group. HCY, homocysteine; HUVECs, human umbilical vein endothelial cells; ov, overexpression; NC, negative control; Bip, ER chaperone BiP.

and triggering endothelial desquamation (21). Therefore, it was used as an elicitor to induce endothelial dysfunction in the present study and the results showed that HCY decreased cell viability, elevated the concentration of inflammatory cytokines and promoted cell apoptosis of HUVECs.

Inflammation is important in the occurrence and development of arteriosclerosis and arteriosclerosis-related complications. NF- $\kappa \mathrm{B}$ is a key transcriptional regulator at the onset of inflammation, and activation of $\mathrm{NF}-\kappa \mathrm{B}$ is extensively involved in different inflammatory diseases, including asthma and rheumatoid arthritis (22-25). Furthermore, NF- $\kappa \mathrm{B}$ activation has been found in atherosclerotic plaques, and specific silencing or inhibition of the NF- $\mathrm{B}$ signaling pathway has been shown to reduce the area of the atherosclerotic plaques and decrease the incidence of atherosclerosis-related complications (26). The results from the present study also suggested that HCY notably increased the protein expressions levels of p-p65 and p-IкB $\alpha$, suggesting that the release of pro-inflammatory cytokines may be associated with the activation of the $\mathrm{NF}-\kappa \mathrm{B}$ signaling pathway.

Propofol is widely used as an anesthetic and it has been reported to possess anti-inflammatory properties (27). A previous study identified its role in alleviating inflammation via the inhibition of the $\mathrm{NF}-\kappa \mathrm{B}$ signaling pathway in allergic asthmatic mice; however, whether it could play a central role in suppressing the NF- $\mathrm{NB}$ signaling pathway to reduce inflammation and cell apoptosis remains unclear (28). In the present study, pretreatment with propofol increased cell viability, 
reduced apoptosis and ameliorated inflammation by inactivating the $\mathrm{NF}-\kappa \mathrm{B}$ signaling pathway.

The ER is a membranous network of branching tubules and flattened sacs in all eukaryotic cells. It is known as a factory where proteins are synthesized, folded, assembled and modified. ERS occurs when there is an imbalance between the protein-folding load and the capacity of ER, as a result of an increasing demand for folding proteins or stimuli that obstruct the proteins to fold (29). Once ERS occurs, UPR is activated through the evolutionally conserved signaling pathways, including IRE1 $\alpha$ and PERK (30). These are two ER-localized protein sensors, both of which possess an ER-luminal domain that senses unfolded proteins, and a cytosolic domain that transmits signals to the transcriptional or translational apparatus. IRE1 $\alpha$ has protein-kinase activity and site-specific endoribonuclease (RNase) activity $(31,32)$. PERK also has protein-kinase activity (33). In response to ERS, IRE1 $\alpha$ is autophosphorylated, thereby activating its RNase activity. As aforementioned by some studies, HCY has been demonstrated to induce ERS in endothelial cells, and propofol can inhibit ERS in the retinal pigment epithelial cells, thus the present study focused on the specific role of propofol in the regulation of ERS in endothelial cells $(34,35)$. The results showed that HCY elevated the protein expression levels of Bip and CHOP, which are ER-specific chaperones and transcriptional factors contributing to apoptosis, respectively. Furthermore, HCY promoted PERK and IRE1 $\alpha$ phosphorylation in HUVECs, thereby leading to ERS. However, increasing doses of propofol could gradually reverse these trends.

In a previous study, hypertensive mouse models were administrated with ERS inhibitors, which led to improved endothelial function, suggesting that ERS might be associated with endothelial dysfunction (36). In addition, the association between ERS and atherosclerosis was also investigated previously and it was confirmed in atheroma endothelial cells and macrophages (37). Thus, in the present study it was hypothesized that propofol could alleviate inflammation and apoptosis of endothelial cells by regulating ERS. To further confirm this hypothesis, ov-Bip was constructed and transfected into the HCY-induced HUVECs, which were pretreated with propofol. The results showed that overexpression of Bip could reverse the inhibitory effects of propofol on ERS and decrease cell viability. Several reports have indicated that inflammatory cytokines can cause ERS and therefore activate the UPR $(10,11,38)$. Thus, the concentration of inflammatory factors was investigated in the present study, and it was found that transfection with ov-Bip could upregulate their concentrations. Not surprisingly, it also reactivated the NF- $\kappa \mathrm{B}$ signaling pathway. The interaction between IRE1 $\alpha$ and PERK can assist with the converge of the distinct signaling pathways to produce an effective response to reduce damage (39). However, if overwhelmed, these signaling proteins can also induce apoptosis (31). Correspondingly, reactivation of these proteins, by the overexpression of Bip, in the present study, could promote cell apoptosis. In addition, propofol has also been reported to inhibit inflammation via other pathways besides the NF- $\kappa \mathrm{B}$ signaling pathway (40-42). Whether propofol may relieve HUVEC injury or arteriosclerosis via other pathways will be investigated in our future studies.
In conclusion, propofol could ameliorate inflammation and cell apoptosis in HCY-induced HUVECs by inhibiting ERS, which may provide a novel insight into the treatment of atherosclerosis. However, this study lacks evidence from in vivo experiments, so in vivo studies that utilize animal models will be performed in our future research to determine the protective effect of propofol against arteriosclerosis.

\section{Acknowledgements}

Not applicable.

\section{Funding}

No funding was received.

\section{Availability of data and materials}

All data generated or analyzed during this study are included in this published article.

\section{Authors' contributions}

$\mathrm{MZ}$ and $\mathrm{CJ}$ contributed to the study conception and design. CJ, HY and JH contributed to the acquisition of the data. WZ contributed to the analysis and interpretation of the data. CJ drafted the initial manuscript and $\mathrm{MZ}$ revised it critically for important intellectual content. MZ and CJ confirm the authenticity of all the raw data. All authors read and approved the final manuscript.

\section{Ethics approval and consent to participate}

Not applicable.

\section{Patient consent for publication}

Not applicable.

\section{Competing interests}

The authors declare that they have no competing interests.

\section{References}

1. Pang X, Liu J, Zhao J, Mao J, Zhang X, Feng L, Han C, Li M, Wang $\mathrm{S}$ and $\mathrm{Wu} \mathrm{D}$ : Homocysteine induces the expression of C-reactive protein via NMDAr-ROS-MAPK-NF- $\kappa \mathrm{B}$ signal pathway in rat vascular smooth muscle cells. Atherosclerosis 236: 73-81, 2014.

2. Li J, Luo M, Xie N, Wang J and Chen L: Curcumin protects endothelial cells against homocysteine induced injury through inhibiting inflammation. Am J Transl Res 8: 4598-4604, 2016.

3. Hales TG and Lambert JJ: The actions of propofol on inhibitory amino acid receptors of bovine adrenomedullary chromaffin cells and rodent central neurones. Br J Pharmacol 104: 619-628, 1991.

4. Mickey BJ, White AT, Arp AM, Leonardi K, Torres MM, Larson AL, Odell DH, Whittingham SA, Beck MM, Jessop JE, et al: Propofol for treatment-resistant depression: A pilot study. Int J Neuropsychopharmacol 21: 1079-1089, 2018.

5. Allaouchiche B, Debon R, Goudable J, Chassard D and Duflo F: Oxidative stress status during exposure to propofol, sevoflurane and desflurane. Anesth Analg 93: 981-985, 2001. 
6. Nesseler N, Launey Y, Isslame S, Flécher E, Lebouvier T, Mallédant Y and Seguin P: Is extracorporeal membrane oxygenation for severe acute respiratory distress syndrome related to intra-abdominal sepsis beneficial? Intensive Care Med 41: 943-945, 2015.

7. Lin C, Sui H, Gu J, Yang X, Deng L, Li W, Ding W, Li D and Yang Y: Effect and mechanism of propofol on myocardial ischemia reperfusion injury in type 2 diabetic rats. Microvase Res 90: 162-168, 2013.

8. Wang S and Smith JD: ABCA1 and nascent HDL biogenesis. Biofactors 40: 547-554, 2014.

9. Cao SS, Luo KL and Shi L: Endoplasmic reticulum stress interacts with inflammation in human diseases. J Cell Physiol 231: 288-294, 2016.

10. Oakes SA and Papa FR: The role of endoplasmic reticulum stress in human pathology. Annu Rev Pathol 10: 173-194, 2015

11. Yang X, Xu H, Hao Y, Zhao L, Cai X, Tian J, Zhang M, Han X, Ma S, Cao J and Jiang Y: Endoplasmic reticulum oxidoreductin $1 \alpha$ mediates hepatic endoplasmic reticulum stress in homocysteine-induced atherosclerosis. Acta Biochim Biophys Sin (Shanghai) 46: 902-910, 2014.

12. Yang S, Wu M, Li X, Zhao R, Zhao Y, Liu L and Wang S: Role of endoplasmic reticulum stress in atherosclerosis and its potential as a therapeutic target. Oxid Med Cell Longev 2020: 9270107, 2020.

13. Ivanova EA and Orekhov AN: The role of endoplasmic reticulum stress and unfolded protein response in atherosclerosis. Int J Mol Sci 17: 193, 2016.

14. Hamczyk MR, Villa-Bellosta R, Quesada V, Gonzalo P, Vidak S, Nevado RM, Andrés-Manzano MJ, Misteli T, López-Otín C and Andrés V: Progerin accelerates atherosclerosis by inducing endoplasmic reticulum stress in vascular smooth muscle cells EMBO Mol Med 11: e9736, 2019.

15. Alberts-Grill N, Denning TL, Rezvan A and Jo H: The role of the vascular dendritic cell network in atherosclerosis. Am J Physiol Cell Physiol 305: C1-C21, 2013.

16. Suwaidi JA, Hamasaki S, Higano ST, Nishimura RA, Holmes DR Jr and Lerman A: Long-term follow-up of patients with mild coronary artery disease and endothelial dysfunction. Circulation 101: 948-954, 2000.

17. Reddy KG, Nair RN, Sheehan HM and Hodgson JM: Evidence that selective endothelial dysfunction may occur in the absence of angiographic or ultrasound atherosclerosis in patients with risk factors for atherosclerosis. J Am Coll Cardiol 23: 833-843, 1994

18. Esper RJ, Nordaby RA, Vilariño JO, Paragano A, Cacharron JL and Machado RA: Endothelial dysfunction: A comprehensive appraisal. Cardiovasc Diabetol 5: 4, 2006.

19. Verma S, Buchanan MR and Anderson TJ: Endothelial function testing as a biomarker of vascular disease. Circulation 108 2054-2059, 2003.

20. Canpolat U, Kocyigit D and Yildirim A: Role of endothelial dysfunction and endocan in atherosclerosis: Point of origin or end point? Angiology 71: 477, 2020.

21. Lai WK and Kan MY: Homocysteine-induced endothelial dysfunction. Ann Nutr Metab 67: 1-12, 2015.

22. Rius J, Guma M, Schachtrup C, Akassoglou K, Zinkernagel AS, Nizet V, Johnson RS, Haddad GG and Karin M: NF-kappaB links innate immunity to the hypoxic response through transcriptional regulation of HIF-1alpha. Nature 453: 807-811, 2008.

23. Tak PP and Firestein GS: NF-kappaB: A key role in inflammatory diseases. J Clin Invest 107: 7-11, 2001.

24. Holgate ST: Cytokine and anti-cytokine therapy for the treatment of asthma and allergic disease. Cytokine 28: 152-157, 2004.

25. Williams RO, Paleolog E and Feldmann M: Cytokine inhibitors in rheumatoid arthritis and other autoimmune diseases. Curr Opin Pharmacol 7: 412-417, 2007.
26. Baldwin AS Jr: The NF-kappa B and I kappa B proteins: New discoveries and insights. Annu Rev Immunol 14: 649-683, 1996.

27. Du QH, Xu YB, Zhang MY, Yun P and He CY: Propofol induces apoptosis and increases gemcitabine sensitivity in pancreatic cancer cells in vitro by inhibition of nuclear factor- $\kappa \mathrm{B}$ activity. World J Gastroenterol 19: 5485-5492, 2013.

28. Peng X, Li C, Yu W, Liu S, Cong Y, Fan G and Qi S: Propofol attenuates hypoxia-induced inflammation in BV2 microglia by inhibiting oxidative stress and $\mathrm{NF}-\kappa \mathrm{B} / \mathrm{Hif}-1 \alpha$ signaling. Biomed Res Int 2020: 8978704, 2020.

29. Zhang K and Kaufman RJ: From endoplasmic-reticulum stress to the inflammatory response. Nature 454: 455-462, 2008.

30. Shamu CE, Cox JS and Walter P: The unfolded-protein-response pathway in yeast. Trends Cell Biol 4: 56-60, 1994.

31. Ron D and Walter P: Signal integration in the endoplasmic reticulum unfolded protein response. Nat Rev Mol Cell Biol 8 : 519-529, 2007.

32. Cox JS, Shamu CE and Walter P: Transcriptional induction of genes encoding endoplasmic reticulum resident proteins requires a transmembrane protein kinase. Cell 73: 1197-1206, 1993.

33. Shi Y, Vattem KM, Sood R, An J, Liang J, Stramm L and Wek RC: Identification and characterization of pancreatic eukaryotic initiation factor 2 alpha-subunit kinase, PEK, involved in translational control. Mol Cell Biol 18: 7499-7509, 1998.

34. Zhu L, Jia F, Wei J, Yu Y, Yu T, Wang Y, Sun J and Luo G Salidroside protects against homocysteine-induced injury in human umbilical vein endothelial cells via the regulation of endoplasmic reticulum stress. Cardiovasc Ther 35: 33-39, 2017.

35. Zhou X, Wei Y, Qiu S, Xu Y, Zhang T and Zhang S: Propofol decreases endoplasmic reticulum stress-mediated apoptosis in retinal pigment epithelial cells. PLoS One 11: e0157590, 2016.

36. Kassan M, Galán M, Partyka M, Saifudeen Z, Henrion D, Trebak M and Matrougui K: Endoplasmic reticulum stress is involved in cardiac damage and vascular endothelial dysfunction in hypertensive mice. Arterioscler Thromb Vasc Biol 32 1652-1661, 2012.

37. Tabas I: The role of endoplasmic reticulum stress in the progression of atherosclerosis. Circ Res 107: 839-850, 2010.

38. Xue X, Piao JH, Nakajima A, Sakon-Komazawa S, Kojima Y, Mori K, Yagita H, Okumura K, Harding $\mathrm{H}$ and Nakano H: Tumor necrosis factor alpha (TNFalpha) induces the unfolded protein response (UPR) in a reactive oxygen species (ROS)-dependent fashion, and the UPR counteracts ROS accumulation by TNFalpha. J Biol Chem 280: 33917-33925, 2005.

39. Sprenkle NT, Sims SG, Sánchez CL and Meares GP: Endoplasmic reticulum stress and inflammation in the central nervous system. Mol Neurodegener 12: 42, 2017.

40. Wu GJ, Lin YW, Chuang CY, Tsai HC and Chen RM: Liver nitrosation and inflammation in septic rats were suppressed by propofol via downregulating TLR4/NF- $\mathrm{BB}$-mediated iNOS and IL-6 gene expressions. Life Sci 195: 25-32, 2018.

41. Ding XW, Sun X, Shen XF, Lu Y, Wang JQ, Sun ZR, Miao CH and Chen JW: Propofol attenuates TNF- $\alpha$-induced MMP-9 expression in human cerebral microvascular endothelial cells by inhibiting $\mathrm{Ca}^{2+} / \mathrm{CAMK} \mathrm{II} / \mathrm{ERK} / \mathrm{NF}-\kappa \mathrm{B}$ signaling pathway. Acta Pharmacol Sin 40: 1303-1313, 2019.

42. Cheng L, Chen Z, Wang L, Lan Y, Zheng L and Wu F: Propofol partially attenuates complete freund's adjuvant-induced neuroinflammation through inhibition of the ERK1/2/NF- $\mathrm{KB}$ pathway. J Cell Biochem 120: 9400-9408, 2019.

This work is licensed under a Creative Commons Attribution-NonCommercial-NoDerivatives 4.0 International (CC BY-NC-ND 4.0) License. 